\author{
Cadernos de \\ ESTUDOS LINGUÍSTIICOS - (59.3), Campinas, pp. 565-579 - set./dez. 2017
}

\title{
FALA E LEITURA: UMA (RE)ENTRADA PARA A ESCRITA
}

\author{
MARIA IRMA HADLER COUDRY* \\ (UNICAMP) \\ FERNANDA MARIA PEREIRA FREIRE** \\ (UNICAMP)
}

\begin{abstract}
RESUMO: O presente artigo focaliza a inter-relação entre a entrada da criança no mundo das letras e a involução que o afásico experimenta no que diz respeito à leitura e escrita, a partir da teorização proposta pela Neurolinguística Discursiva, chamando a atenção, em especial, para o ajuste que o falante (criança ou afásico) faz ao ler palavras depois de escrevê-las, para que a escrita que propôs se ajuste à fala que lê, diferente de como diz a palavra sem a escrita como apoio. Para tanto, analisamos dados de escrita de uma criança e de dois afásicos, que se encontram em momentos diferentes em relação à retomada da escrita, com base em uma metodologia heurística que busca descobrir o que está encoberto pelas dificuldades escolares e pela afasia e o que se desponta nessa descoberta. Os resultados mostram caminhos comuns que crianças e afásicos tomam e, assim, contribuem para uma maior compreensão tanto do processo normal de aquisição e uso da escrita quanto de processos patológicos que ocorrem na afasia.
\end{abstract}

Palavras-chave: afasia, infância, fala, leitura, escrita, Neurolinguística Discursiva

\begin{abstract}
This article focuses on the interrelation between the child's writing acquisition process and the involution that the aphasic experiences with regard to speech, reading and writing. The theorization comes from Discursive Neurolinguistics, especially to the adjustment that the speaker (child or aphasic) makes when reading words after writing them, so that the writing he proposes fits into the speech he reads, different from what occurs when he says the word without writing as support. To achieve our goal, we analyze the writing data of a child and two aphasics who are at different points in the process of writing restoration, based on a heuristic methodology that seeks to discover what is hidden by school difficulties and aphasia and what emerges in this discovery. The results show common paths that children and aphasics take and this contributes to a greater understanding of normal acquisition process and use of writing as well as the pathological processes that occur in aphasia.
\end{abstract}

Keywords: aphasia, childhood, speech, reading, writing, Discursive Neurolinguistics

\footnotetext{
* coudry@iel.unicamp.br

** ffreire@unicamp.br
} 


\section{INTRODUÇ̃̃OO}

Dando continuidade ao estudo neurolinguístico empreendido por vários pesquisadores da área de Neurolinguística Discursiva (ND) que focalizam a tríade fala, leitura e escrita, e a inter-relação entre a entrada da criança no mundo das letras e a involução que o afásico experimenta, este texto põe em relevo o modo como a criança lê palavras que escreve, em suas primeiras tentativas de leitura, e o modo como o adulto também o faz, quando apresenta uma afasia ${ }^{1}$ que modifica sua relação com a leitura, voltando a ler como na infância.

Muitas de nossas pesquisas sobre a escrita com afásicos no processo de retomada e, também, com crianças que a experimentam pela primeira vez, mostram a presença da fala em sua produção, seja ao falar enquanto escrevem, seja ao dizer o que pretendem escrever e, ainda, ao ler em voz alta o que escreveram. Neste texto chamamos a atenção para um certo ajuste que o falante faz ao ler palavras depois de escrevê-las, para que a escrita que propôs se ajuste à fala que lê, diferente de como diz a palavra sem a escrita como apoio. Esse modo de ler incide no ritmo da língua.

Vale a pena explicitar, considerando o debate que se faz entre diferenças e semelhanças relativas ao ritmo da fala e ao ritmo da escrita, que nossa intervenção se faz para que a criança e o afásico entrem - de primeira e de novo - na escrita, mediados pela fala, com ênfase na sílaba, unidade da fala. Trata-se de uma leitura que passa pela fala, ou seja, criança e afásico leem as palavras que escreveram em voz alta. Isso põe em relevo algo que não ocorre quando linguistas diferenciam o ritmo da fala daquele da escrita, como o faz Chacon (1998), considerando fala e escrita como dois sistemas semióticos relacionados, mas distintos, com ritmos distintos. Ou como Barbosa (2013), que postula congruências e incongruências entre os dois ritmos mediante três balizas (periodicidade, estruturação e movimento/novidade) que aproximam as duas experiências rítmicas: a da fala vinculada à audição, e tendo como unidade mínima a sílaba fonética, e a da escrita vinculada à visão, que tem a letra como unidade.

Abaurre (2003) nos dá argumentos interessantes para analisar a leitura de palavras pela criança e pelo afásico: reconhecer no ritmo um lugar de (re) organização, tanto da fala quanto da escrita, em seus vários níveis de estruturação. Ler silabicamente provoca uma certa ordem no intervalo entre os constituintes lidos que coincide com o número de 2 caracteres $(\mathrm{CV})$ e ao final da palavra não pode sobrar nenhum deles sem ser falado, como se houvesse um pareamento entre $\mathrm{o}$ escrito e o falado. Ambos, criança e afásico, alongam a fala para corresponder aos caracteres. ${ }^{2}$

${ }^{1}$ A afasia decorre de uma lesão córtico-cerebral adquirida que afeta sistemas funcionais complexos (LURIA, 1977) envolvidos na linguagem; afeta processos de significação relacionados a um ou mais níveis de análise linguística, bem como sua inter-relação, modificando a familiaridade que o falante tem com a linguagem em suas várias funções e incidindo também sobre o discurso e a (inter) subjetividade (COUDRY, 1986, 2010).

${ }^{2}$ Tal como muitos professores de anos iniciais fazem na tentativa de parear a relação som/letra, especialmente em atividades como o ditado. 
Também a reflexão de Cagliari (2013) sobre ritmo ajuda a compreender esse fenômeno: a criança que ainda não domina a escrita e o afásico que deixa de dominar conferem um ritmo silábico à fala quando leem. É como se afásico e criança lessem todas as letras da palavra em um ritmo silábico, lexical, de forma diferente de como a pronunciam na fala, separada de sua forma gráfica e articulada a outras palavras, pós-lexicalmente, configurando um ritmo acentual para o Português do Brasil (PB), conforme analisam o autor e as autoras Migliorini e Massini-Cagliari (2010). A atividade linguística de escrever palavras dá lugar a uma atividade epilinguística que se cruza com uma reflexão de natureza metalinguística na tentativa de desvendar a própria escrita. Por outro lado, estudos de Abaurre-Gnerre (1981) e Abaurre (2003) argumentam em favor de um ritmo misto para o PB, assim como Bisol (2000) e Barbosa (2000). Barbosa (2013) reanalisa a questão e apresenta vários argumentos para considerar o PB como uma língua acentual, havendo certos contextos em que um ritmo silábico pode acontecer, como nossos dados mostram. Mesmo considerando o PB uma língua de ritmo acentual, pode acontecer um ritmo silábico, conforme pontua Abaurre-Gnerre (1981), em uma fala mais formal ou mais lenta, tal como ocorre com (re)aprendizes de escrita. É como se a duração das sílabas servisse à leitura vozeada para corresponder às unidades gráficas. Com a automatização da escrita/leitura a duração das sílabas é fixada, com valores determinados pela língua, conforme indica Cagliari (2013), o que a criança já faz em relação à fala e o afásico também (desde que não apresente dificuldades articulatórias que intervenham em sua fala), embora possa haver alguma hesitação tanto de um quanto de outro em palavras desconhecidas ou não reconhecidas. Barbosa (2013) retoma a concepção de ritmo da escrita definido por Abaurre (1991), relacionado "ao modo como um texto 'respira' depois que o gesto rítmico com o qual foi produzido se 'congela' em signos gráficos sobre uma página em branco" (op. cit. p. 78).

Em nossa pesquisa, observamos que a criança, que ainda não domina a relação entre gestos articulatórios e sua representação gráfica, e o afásico, que volta a se encontrar na mesma condição, não têm essa relação automatizada, deslizam no controle pneumofônico e ajustam a leitura a uma fala silabada, para destacar certos aspectos da palavra escrita. Observamos, ainda, que mesmo o afásico escolarizado, com conhecimento formal do que é uma palavra e uma sílaba, e a criança lidando, intuitivamente, com a sílaba como unidade de fala, ambos funcionam da mesma forma nessa espécie de leitura inicial da unidade da escrita, a palavra.

Para discutir essa questão, serão apresentados dados, e proposta sua análise, de crianças e de afásicos em situações de escrita em que: (i) um segmento da palavra é omitido ao escrever e expandido em sua leitura; (ii) um segmento é inserido na leitura do que se escreve; (ii) um segmento é inserido na escrita da palavra e omitido na leitura; (iv) diferentes sílabas complexas são escritas como simples. ${ }^{3}$

Os resultados, produzidos por sujeitos diante de um sistema em estruturação (aquisição) e em desestruturação (afasia), mostram caminhos comuns que crianças e afásicos tomam e, assim, contribuem para uma maior compreensão tanto do processo

${ }^{3}$ Seguimos também Amaral et alli (2010) que descrevem e analisam características da sílaba e omissões ortográficas na escrita infantil. 
normal de aquisição e uso da escrita quanto de processos patológicos que ocorrem na afasia. Analisamos, sobretudo, a escrita de sujeitos que vivem momentos diferentes no eixo do tempo e nas vivências com a linguagem: a criança no processo de entrar para o sistema da língua e seu uso e o afásico tendo interrompidas e modificadas diversas entradas no sistema da língua e em seu uso.

Do ponto de vista metodológico, lançamos mão de um estudo que relaciona dados de escrita de uma criança (RF) e de dois afásicos (GF e BR) que se encontram em momentos diferentes em relação à retomada da escrita, por meio de acompanhamento longitudinal e da metodologia heurística que busca descobrir, no processo, o que está encoberto pelas dificuldades escolares e pela afasia e o que se desponta nessa descoberta. Busca-se, portanto, o dado-achado (COUDRY, 1996) - que ilumina o processo e expõe o acontecimento discursivo, movimentando a teorização e fazendo avançar a análise. Reunimos, assim, dados de RF, GF e BC, produzidos em ambiente discursivo experimental que, diferentemente dos testes, não são usados para avaliar tais sujeitos, mas para conhecer e comparar processos que se encontram e que se distanciam: uma metodologia que mantém os mesmos contextos de ocorrência para comparar esses pontos de encontro no sistema e de distanciamento no processo.

Os dados a serem apresentados são produzidos no Centro de Convivência de Afásicos $\left(\mathrm{CCA}^{4}\right)$ e no Centro de Convivência de Linguagens (CCazinho ${ }^{5}$, lugares discursivos de acontecimento de práticas com a linguagem que envolvem vários tipos de atividades que representam a concepção de linguagem, sujeito e cérebro como construtos humanos, delineados pelo face biológica do homem e produzidos/determinados pela história da humanidade.

${ }^{4}$ O Centro de Convivência de Afásicos foi criado em 1989, mediante um convênio interdisciplinar entre o Departamento de Linguística, do Instituto de Estudos da Linguagem, com o Departamento de Neurologia, da Faculdade de Ciências Médicas, da Universidade Estadual de Campinas (São Paulo/ Brasil). Atualmente são três grupos, conduzidos pelas três docentes responsáveis pela área de Neurolinguística. O Grupo II é o focalizado neste texto. O CCA dedica-se ao estudo da afasia e desenvolvimento de práticas com a linguagem, orientadas discursivamente, integradas na avaliação e acompanhamento longitudinal. Fazemos no CCA o que fazemos no mundo em que vivemos: falamos, lemos, escrevemos (agenda, palavras, receitas, narrativas), digitamos, comentamos, contamos, jogamos, vivenciando, em resumo, o conjunto de experiências com a linguagem que os sujeitos pragmáticos têm em sua vida. Visamos a retomada da linguagem, em suas várias faces, em interação com outros interlocutores, afásicos e não afásicos. Nesse ambiente discursivo, acontecem, para lidar com a linguagem nas afasias, processos alternativos de significação (COUDRY, 1986) de que afásicos se servem para se inserirem, da melhor forma possível, num mundo em que o discurso, e os dispositivos (FOUCAULT, 1969; AGAMBEN, 2009) que o condicionam, se apresenta como uma qualidade genuinamente humana.

${ }^{5}$ O Centro de Convivência de Linguagens, CCazinho, foi criado, em 2004, por iniciativa da Profa. Maria Irma Hadler Coudry, para acolher crianças com dificuldades escolares que são enfrentadas no acompanhamento longitudinal. Nesse grupo se desenvolve um trabalho que integra fala, leitura e escrita com crianças e jovens que apresentam dificuldades escolares, muitas das quais receberam diagnósticos neurológicos (relativos a: Dificuldade de Aprendizagem, Dislexia, Déficit de Atenção com e sem Hiperatividade, Déficit no Processamento Auditivo, Déficit Intelectual) que produzem efeitos negativos em seu processo de escolarização e em sua vida. Nosso foco são as crianças e suas famílias, e não seus diagnósticos. Pretende-se formar crianças leitoras e escreventes, o que propicia autonomia linguística, condição que se almeja. Todos nos envolvemos em diversas práticas discursivas com as crianças para motivá-las a entrar na leitura/escrita e lidamos com elas como seres de seu tempo, o que significa saber do que gostam, fazem, além de expandir e criar novos interesses. 
AFASIA E INFÂNCIA: PRESSUPOSTOS DA ND

Como já foi dito, a afasia desorganiza a base fonográfica que sustenta a escrita alfabética e a criança está em processo de automatizá-la. ${ }^{6} \mathrm{~A}$ estruturação da sílaba mostra isso. Seguindo Abaurre (2001), "a criança precisa decidir primeiro sobre o número de segmentos a serem representados e depois sobre a posição de cada um na estrutura da sílaba (o que descaracteriza o que se convencionou chamar de "troca de letras')" (Abaurre, op. cit. pp. 70-71).

A relação entre afasia e infância aparece nos primeiros estudos discursivos da afasia com base em De Lemos (1982): processos dialógicos na fala do afásico e da criança (COUDRY, 1986). Coudry e Bordin (2012) e Bordin e Coudry (2015) retomam radicalmente essa relação com base em Jakobson (1941), Freud (1891), Heller-Roazen (2005). Seguindo esses autores, reafirmamos que o afásico sai do sistema da língua (o que afeta a fala, a leitura e escrita) e os dados mostram suas tentativas de (re)entrar nesses sistemas. Por outro lado, a criança já dominando a fala, lugar do sentido para ela, tem esta como âncora inicial para entrar no sistema alfabético. É interessante como a reflexão que o espaço da escrita possibilita tem efeitos na estabilização de relações de diferença no sistema (LURIA, 1988; POSSENTI, 2005; ALKMIM, 2009). A escrita se organiza pela ação da atividade epilinguística (CULIOLI, 1999; COUDRY, 1986; COUDRY e BORDIN, 2012) que se desdobra em nossa intuição de sujeito falante. A comparação entre afasia e linguagem infantil que temos realizado, portanto, contribui fortemente para compreendermos as modificações advindas da afasia que afetam a escrita, por um lado, e o processo de entrada da criança no sistema alfabético, por outro.

Freud (1891) vislumbra uma aproximação entre criança e afásico. Ele concebe a afasia como uma modificação funcional que interrompe os diferentes graus de intimidade que construímos pela vida com a linguagem (fala, leitura e escrita) e com os sujeitos com quem falamos e que falam conosco (BENVENISTE, 1966), o que pressupõe uma escuta. Tal aproximação é possível pelo conceito de dissolução do neurologista H. Jackson (1874), que caracteriza o estado afásico como uma impossibilidade para formar proposições e relacionar palavras, ou seja, produzir enunciados.

Aprende-se com Jakobson (1941) que o afásico retorna a caminhos há muito esquecidos e a criança trilha por caminhos que serão apagados por constrições do sistema a que se submete em sua língua materna. E nesses caminhos se cruzam processos comuns para o afásico e o aprendiz de linguagem, ${ }^{7}$ conforme mostram Coudry (2010) e Coudry e Bordin (2012). Dados de escrita de crianças e afásicos têm mostrado essa aproximação: a busca pela posição das letras em sílabas complexas é um lugar de encontro para os dois que hesitam e oferecem escritas

\footnotetext{
${ }^{6}$ Em Freire et alii. 2013, exploramos essa ideia, no texto "Entre lápis e teclas: selecionando e combinando letras" que publicamos no Cadernos de Estudos Linguísticos.

${ }^{7}$ Isso não quer dizer que o afásico possa ser tomado como uma criança, o que, erroneamente, alguns profissionais fazem, submetendo-o a atividades descontextualizadas e infantilizadas que o distanciam ainda mais do exercício da linguagem e, consequentemente, da possibilidade de reconstrui-la como sujeito da linguagem. Para maiores detalhes ver Labigalini (2009).
} 
possíveis e aproximações diante do preenchimento ou não de certas posições; o movimento da escrita para a fala e vice-versa; o apoio na soletração para escrever; o ajuste da fala à leitura do que escreve, seja omitindo ou inserindo segmentos na escrita ou na leitura.

O que para crianças em fase de aprendizagem torna-se automatizado (COUDRY e SCARPA, 1985) ${ }^{8}$ depois de algum tempo em que escrevem, leem, reescrevem, fazendo com que não mais necessitem da imagem visual no processo de escrita (tornando-se possível, dessa maneira, escrever no escuro, por exemplo), é desautomatizado na afasia, fazendo com que o afásico precise novamente do elemento visual. Outra desautomatização na afasia verbal é a não concomitância entre percepção acústica/sonora, visual e ação motora/gestos articulatórios, como se verá adiante nos dados dos afásicos, que precisam falar para escrever e reescrever.

Resumimos, a seguir, as bases teóricas que temos reelaborado para dar conta do movimento teoria/dado que caracteriza nossos estudos, retomando uma passagem que mostra a contribuição de Freud para o estudo da aprendizagem da leitura e da escrita:

"Freud constrói, então, hipoteticamente, um aparelho de linguagem destinado a associar as palavras a partir das experiências de sentido do sujeito no corpo e na língua. Ele também analisa como a fala, que veicula sentidos da e na linguagem/língua, materializa-se em aspectos físicos (motor, visual, acústico, proprioceptivo, cinestésico), os quais suscitam diferentes percepções por parte da criança em sua entrada na fala/linguagem, para, posteriormente, tornarem-se automáticas.

Para o autor, o aparelho de linguagem/memória, por ocasião da entrada da criança na leitura e na escrita, se sofistica como base para tais processos. Assim, a aprendizagem da escrita e da leitura ativa um sistema complexo que envolve o trabalho linguístico (língua, linguagem, sentido) realizado pela criança desde o seu nascimento. Processo que se soma à coordenação da mão e do olho exigido no desenho da letra; memorização de sua correspondência sonora; memorização da convenção ortográfica e das normas da língua escrita; além da exigência de estabilizar o sentido que será representado por um conjunto de letras. Conjunto de letras que precisa ser decomposto na escrita e recomposto na leitura. Para Freud, a leitura está mais próxima da fala do que a escrita, por ser na fala que o sentido transita. A relevância de retomar a teorização de Freud está em compreender a heterogeneidade dos caminhos que as crianças percorrem para entrar no mundo da leitura e da escrita, reconhecendo que nem todas entram nele da mesma maneira e no mesmo ritmo" (BORDIN e COUDRY, 2015, pp. 131-133).

Temos tomado, portanto, a escrita como um lugar de encontro de processos vivenciados pela criança, aprendiz, e pelo afásico, reaprendiz. Os dados mostram que os afásicos se lembram de processos primitivos pelos quais passou na infância (esquecidos pela criança) e que a criança trilha por caminhos que serão esquecidos ao entrar em um sistema linguístico (lembrados pelo afásico). É interessante a relação entre esquecer e lembrar nas duas pontas do processo de humanização: quando entramos na linguagem e quando ela nos escapa.

${ }^{8}$ Comentando a fala como referência inicial para as crianças escreverem, e como isso é comum e normal, as autoras observam que no processo de aprendizagem o que já se sabe de uma atividade transita para outra, até que os domínios cognitivos que as envolvem atinjam "um grau de autonomia que dispense recorrer a domínios conexos" (COUDRY e SCARPA, 1985). 


\section{SUJEITOS DO ESTUDO EXPERIMENTAL}

RF, sexo masculino, nasceu em 12/02/2008 e começou a frequentar o CCazinho no $2 \mathrm{~s} / 2015$, por intermédio de um primo que também frequenta $o$ Centro. Nascido em Campinas, RF teve um desenvolvimento normal, de acordo com a mãe, embora seja muito tímido. Mora com os pais e um irmão mais velho de 15 anos. A mãe estudou até o $2^{\circ}$ ano do Ensino Médio e trabalha como recepcionista em uma imobiliária; o pai estudou até o $5^{\circ}$ do Ensino Fundamental e é pintor. Segundo a mãe, no início da vida escolar de RF, uma professora disse a ele que não iria aprender e isso ficou muito marcado em sua memória. Ele chorava, dizendo que era burro. Em 2015 mudou de escola, saindo de uma pública para uma escola particular contando com auxílio de uma bolsa social. A mãe disse que ele tem mudado: está menos tímido, fala um pouco mais alto, o que melhora a inteligibilidade por parte do outro, mostrando-se mais seguro; disse, ainda, que ele lê e entende o que está lendo.

RF está no $3^{\circ}$ ano, estuda no período da tarde e frequenta aulas de reforço na escola duas vezes por semana. No dia do seu primeiro acompanhamento em 2016 no CCazinho, RF disse que a atividade da aula de reforço tinha sido escrever várias vezes o alfabeto em letra cursiva maiúscula e minúscula.

A pediatra de RF solicitou exames auditivos por entender que o seu quadro sugeria Doença do processamento auditivo, já que a criança apresentava dificuldade escolar desde o início da vida escolar. A audiometria, datada de junho de 2015, mostrou-se sem alterações, mas a avaliação do Processamento Auditivo concluiu que, após a aplicação de seis testes realizados em uma sessão, na qual a criança se manteve atenta, apresenta desordem do processamento auditivo, do tipo Decodificação e Prosódia.

Em termos de escrita, como a maioria dos aprendizes, escreve como fala; faz hipóteses para escrever como escreve e lê como escreve mostrando suas hipóteses, como veremos em seus dados.

Como RF está aprendendo a escrever, duvida (no bom sentido) de sua produção, ocasião em que corrige o que não precisa corrigir, por exemplo, ao escrever ves para "vez", lê em voz alta veis ${ }^{9}$ e reescreve como fala: veis, produzindo uma epêntese vocálica (CAGLIARI, 2012).

GF, um dos afásicos do nosso estudo, também é do sexo masculino, destro, tem 23 anos e apresenta uma afasia verbal (FREUD, 1891) acompanhada de uma hemiplegia à direita, decorrente de um traumatismo cranioencefálico. GF chegou ao CCA no $1^{\circ}$ semestre de $2012 \mathrm{e}$, durante sua avaliação, falou pouco e, em alguns momentos, recorreu à escrita e a gestos. Quando perguntamos sua idade, mostrou o dedo indicador e médio para dizer o número 2 , em seguida, a investigadora the deu um papel e GF escreveu 19 e também o 2, querendo dizer que tinha 19 e estava para completar 20 anos.

\footnotetext{
${ }^{9}$ Para facilitar a leitura, adotamos o uso do itálico para as produções dos sujeitos; e o uso de aspas para a produção-alvo.
} 
GF foi atropelado em setembro de 2010, quando estava com 18 anos, por um caminhão quando saía de seu trabalho. Levado ao hospital, GF necessitou de uma craniotomia, em que se constatou uma lesão nos lobos frontal, temporal e parietal no hemisfério esquerdo. Na época, frequentava o $3^{\circ}$ ano do Ensino Médio no período noturno e trabalhava durante o dia em uma empresa. GF tem apresentado melhora em sua fala, e mantendo dificuldades de leitura e de escrita, que também estão se modificando (FREUD, 1891). Além de frequentar o CCA, estuda em uma escola do município em que mora, onde cursa o Ensino de Jovens e Adultos (EJA).

$\mathrm{BC}$, o outro afásico, também é do sexo masculino, destro, tem 29 anos e apresenta uma afasia verbal (FREUD, 1891) devido a um Acidente Vascular Encefálico Isquêmico (AVEI), ocorrido em julho de 2012, em função de uma dissecção da carótida por um problema congênito. Como sequelas do AVEI, BC apresenta hemiparesia direita de membro superior e inferior e afasia por lesão têmporo-parietal esquerda. Seu quadro afásico inicial se caracteriza por uma estereotipia que ocupava o lugar das palavras, além de dificuldades de leitura e escrita. Embora já tenha apresentado progressos significativos, sobretudo na fala, ainda apresenta uma escrita permeada de paragrafias, marcada por episódios de refacção (ABAURRE et alli, 1997), até reescrever a palavra ortograficamente.

\section{CONTEXTUALIZAÇÃO E APRESENTAÇÃO DOS DADOS}

Compartilhamos com Abaurre et alli (1997) que o processo de entrar no mundo das letras é "um momento singular de um processo mais geral de aquisição da linguagem" em que o aprendiz "reconstrói a história de sua relação com a linguagem" pelo "contato com a representação escrita da língua que fala" (op. cit. p. 22), o que também se aplica à afasia. Abaurre e Coudry (2008) retomam a relação entre afasia e escrita inicial, motivadas pela atividade epilinguística/reflexiva que ocorre, de maneira especial, com afásicos e crianças, que rearranjam o que foi escrito em reescrita, apontando a natureza incompleta da linguagem.

Isso envolve dominar o sistema alfabético e ortográfico, em (re)aquisição, além dos diversos critérios de textualidade que compõem os vários gêneros discursivos com os quais a criança e o afásico se envolvem como sujeitos da linguagem e da sociedade. Notamos, como muitos linguistas já apontaram, que é normal a presença da fala no que se escreve no início do processo, o que deixa de acontecer quando a escrita adquire autonomia, uma espécie de vida própria em relação à fala (cf. nota 7).

Analisamos, a seguir, dados de RF, GF e BC para ilustrar tanto a metodologia (que incide em procedimentos de descoberta da afasia e do momento no processo de (re)entrar na escrita por que passam os sujeitos) quanto com que olhos teóricos interpretamos o movimento do sujeito na linguagem.

Os dados foram produzidos em meio à leitura e recontagem de um texto, a partir do qual trabalhamos com a escrita de palavras como um sistema de representação da relação entre som e letra que acontece em práticas sociais/ discursivas (MAINGUENEAU, 1989), dirigidas a outros, com várias funções 
que asseguram propriedades estáveis, considerando sua inserção na história da humanidade, conforme discutem Massini-Cagliari e Cagliari (2001). Da mesma forma consideramos a permanência e a regularidade das representações fonográficas no sistema (FARACO, 2012) bem como a sua heterogeneidade e dialogicidade (BAKHTIN, 2003; CORRÊA, 2004) em relação a seu modo de se constituir e de se inserir, tal como a fala, em discursos anteriores.

Convém esclarecer que, além de semelhanças, há singularidades na relação da criança e do afásico com a linguagem: ela tem a fala (o velho) por onde passa o sentido e pode contar com ela como apoio para a escrita (o novo); ele, como não tem mais a fala sem afasia a sua disposição, precisa repetir/escutar várias vezes a fala do outro e a dele em voz alta para retomar sua representação mental, sua impressão motora e acústica para escrever (FREUD, 1891). Na escrita da criança e do afásico interfere a variedade de fala. Em resumo, RF se apoia no conhecido; GF e BC têm que contar ora com este, ora com o novo e ora com nenhum. Para RF a fala é sempre o velho e a escrita o novo, um novo que se tornará velho; para GF e BC não é possível prever quando um ou outro assumem o lugar de velho e de novo. Além disso, a fala com afasia às vezes atrapalha a recuperação do velho da língua, como analisa Coudry $(2008,2010)$ com base em Freud (1891). Os afásicos apresentam uma maior vulnerabilidade na cadeia de significantes, seja ao falar, seja ao escrever, o que pode se revelar em parafasia, paralexias e paragrafias, até alcançarem (ou não) a palavra-alvo, como mostram alguns dados de GF e BC.

Vejamos as produções dos sujeitos na tentativa de escrever e ler as palavras "exclamou", "sugestão" e "imensa" que apresentam lugares de complexidade para serem escritas: sílaba complexa, ortografia e representação nasal.

Dado 1: Escrita da palavra "exclamou"

\begin{tabular}{|c|c|c|}
\hline RF & GF & $\mathrm{BC}$ \\
\hline $\begin{array}{l}\text { Deglame } \\
\text { esglamou }\end{array}$ & $\begin{array}{c}\text { escri } \\
\text { esclomsere } \\
\text { escri } \\
\text { classe } \\
\text { esclasse } \\
\text { esclamou }\end{array}$ & $\begin{array}{l}\text { isceomou } \\
\text { izce } \\
\text { excemou (en) } \\
\text { esclamou } \\
\text { ezcl*1 } \\
\text { exclamou* }\end{array}$ \\
\hline es-cla-mo-u & es-cla-mo-u & es-cla-mo \\
\hline
\end{tabular}

${ }^{10}$ As produções escritas marcadas com asterisco (*) são reescritas após a leitura da própria produção; as demais são tentativas de aproximação da palavra-alvo realizadas antes da leitura em voz alta. As palavras em itálico, na última linha da tabela, correspondem à leitura em voz alta realizada pelos sujeitos após a escrita final da palavra. 
RF e GF ajustam a fala à escrita ao lerem em voz alta a palavra, para dar relevo ao som final $u$, lugar em que ambos hesitaram na escrita, uma vez que, como muitos falantes, nenhum deles na fala espontânea sonoriza essa coda silábica (exclamo), exatamente como BC lê sua produção final. RF e GF leem es-cla-mo-u: a escrita, portanto, orienta a fala com a qual leem o que escreveram; ambos inserem um segmento na leitura que fazem. Um ponto comum entre todos é que se orientam foneticamente (e não ortograficamente) para escreverem a palavra exclamou: usam $\mathrm{o} / \mathrm{s} /$ no lugar da letra " $\mathrm{x}$ " que tem várias representações sonoras.

Vejamos separadamente o que cada um faz. A escrita de RF revela a instabilidade do traço de sonoridade na escrita (exglamou), que não se revela na fala. O modo de ler a palavra, mostra como a criança de uma variedade não padrão chega a uma fala cuidada, mais próxima à escrita ortográfica. $\mathrm{O}$ alongamento da fala de RF para se ajustar às letras dispostas no papel, provavelmente é motivada pela ideia de que há uma correspondência direta entre o que escreve e o que lê, o que desaparecerá à medida que o processo avança e ele passar a ler palavras e não mais se apoiar em seus segmentos que, no início, decompõe soletrando e recompõe escrevendo unidades de sentido, palavras da língua.

GF, ao escrever "exclamou" vem à tona o modo como fala a palavra: escramou, o que resulta na sua primeira tentativa de escrita (escri). Interpelado pela investigadora para dizer uma palavra com a sílaba cla, diz e escreve classe, o que motiva a paragrafia esclasse e, finalmente, escreve exclamou.

$\mathrm{BC}$ escreve foneticamente a palavra (esclamou) e a lê como a diz espontâneamente, recorrendo ao velho da língua. Interpelado pela investigadora sobre a ortografia convencional da palavra, apresenta dificuldade para registrar a letra " $x$ " que na primeira tentativa se aproxima de um " $z$ ", até atingir uma forma mais próxima à letra-alvo.

Veja-se, agora, o que ocorre quando são convidados a escrever a palavra "sugestão".

Dado 2: Escrita da palavra "sugestão"

\begin{tabular}{|c|c|c|}
\hline RF & GF & $\mathrm{BC}$ \\
\hline $\begin{array}{l}\text { hegestan } \\
\text { chugestano }\end{array}$ & $\begin{array}{l}\text { xygeppóa } \\
\text { sugestâa } \\
\text { jugejão**11 } \\
\text { sugestão }\end{array}$ & 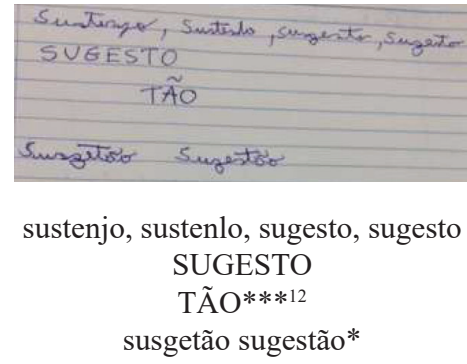 \\
\hline chu-ges-tã-o & su-ges-tão & su-ges-tão \\
\hline
\end{tabular}

${ }^{11}$ Os dois asteriscos indicam que o sujeito fala enquanto escreve.

${ }^{12}$ Os três asteriscos $(* * *)$ indicam uma escrita feita pela invetigadora. 
Este dado mostra a interferência da fala na escrita da criança motivada por uma aquisição ainda incompleta da diferença entre sons próximos e uma indiferenciação, por parte do afásico GF, desses mesmos sons, o que faz com que ele repita, reiteradamente, os dois sons ( $s u$ e $c h u$ ) enquanto escreve. A criança (RF) que ainda não adquiriu o fonema $s u$ e põe o chu no seu lugar, tanto na escrita quanto na fala, e o afásico (GF) que volta a hesitar entre $s u$ e $j u$. RF, no entanto, meses depois, foi capaz de diferenciar $s u$ de $c h u$ ao escrever corretamente a palavra "chuva".

RF não sabe, ainda, marcar ortograficamente a nasalidade da sílaba final (ão/no), embora reconheça que há algo nesse lugar da palavra que aparece como uma vogal nasal na leitura silabada que faz (chu-ges-tã-o): o segmento inserido na escrita não é interpretado como uma letra (n), mas como um som nasalizado (ã). Tampouco BC sabe marcar a nasalidade, como mostram suas tentativas de escrita, nas quais parece hesitar na escolha da ordem das letras para marcar a coda. Embora omita um segmento na escrita (sugesto), lê a palavra silabicamente como se o segmento estivesse presente (su-ges-tão) e aponta para a última sílaba demonstrando que falta algo. A investigadora escreve a sílaba TÃO, cobre-a com o dedo na sequência, e ele escreve a palavra-alvo.

GF, por sua vez, perdeu a familiaridade com os sons da língua, o que fica visível na repetição flutuante e com entonação de estranhamento da sílaba inicial da palavra ( $\mathrm{su} / \mathrm{ju} / \mathrm{chu})$ ao tentar escrevê-la antes que se fixe o caráter permanente e estável do registro escrito (FARACO, 2012).

Dado 3: Escrita da palavra "imensa"

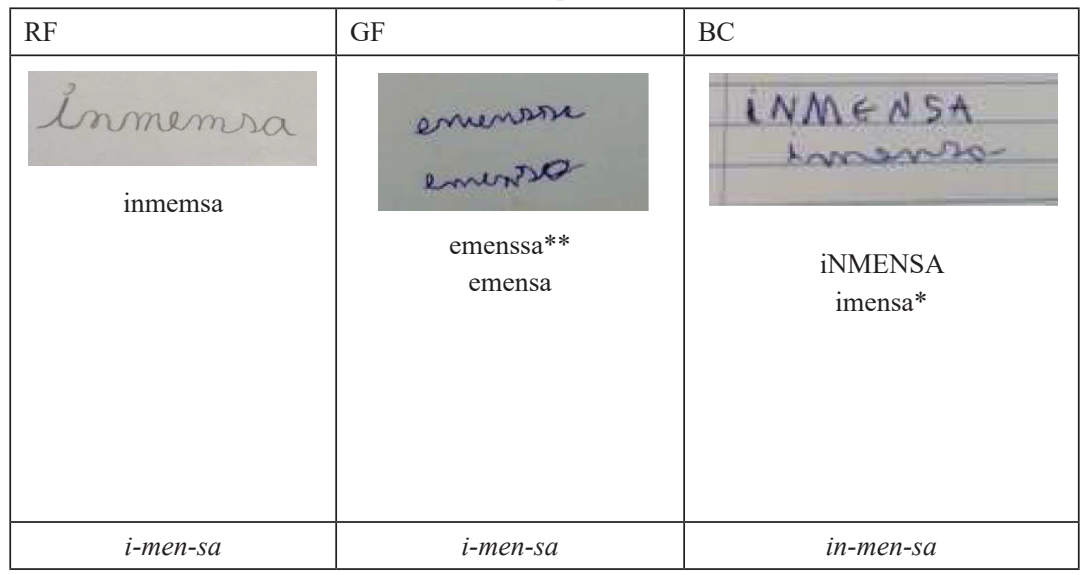

Esse dado mostra que a representação da nasal em PB pode ser uma questão tanto para a criança quanto para o afásico. No caso desses sujeitos em particular, há uma proximidade maior entre a criança $(\mathrm{RF})$ e o afásico $(\mathrm{BC})$ do que entre os dois afásicos. Isso poderia ser diferente se a criança estivesse em um momento anterior do processo de aquisição da escrita, o que a aproximaria mais de GF que apresenta uma afasia mais grave do que $\mathrm{BC}$ atualmente. 
O que há de comum entre RF e BC? Ambos escrevem da mesma forma a palavra, exceto no que diz respeito ao conhecimento da forma ortográfica, que $\mathrm{BC}$ se lembra e RF ainda não fixou (só se usa $\mathrm{M}$ antes de $\mathrm{p}$ e b). BC na leitura é fiel à escrita, marcando a nasalidade na primeira sílaba, o que não ocorre nem com RF nem com GF que, embora não tenham grafado a palavra ortograficamente, leem como falam, mas silabando. O modo como BC lê o que escreveu causa um certo estranhamento nele próprio, o que o leva a reescrever a palavra de forma ortográfica; no caso de RF, ela não reescreve porque na leitura que faz não percebe nenhuma incongruência.

GF nem sempre consegue escrever sem falar, como fez no Dado 1. No entanto, GF escreve o E pelo I e SS por S em contextos possíveis de ocorrência, tal como os aprendizes de escrita o fazem, reafirmando um lugar de encontro entre dados de afasia e de iniciantes de escrita. É interessante que GF embora apresente uma afasia mais grave do que a de $\mathrm{BC}$, não hesita diante da representação da nasal, que supostamente é mais complexo o que os erros que comete, mostrando que as lembranças na afasia não ocorrem cronologicamente, o que as tornam não previsíveis, dependentes das práticas linguageiras e sociais de que participa, como um (inter)locutor ativo que cria condições para que ocorra a neurogênese.

\section{PALAVRAS FINAIS}

Terminamos nosso texto com o ponto crucial de nossa homenagem, ${ }^{13}$ a mais genuína que podíamos lhe prestar: apresentar dados da afasia ${ }^{14}$ de EA, seu pai, de maio de 1994, quando foi avaliado por Coudry, ${ }^{15}$ em sua residência em meio a sua rotina, contando também com a participação de sua filha, Maria Bernadete (MB). São dados de leitura e escrita, mediados pela fala, registrados em áudio, que fazem avançar a relação primordial entre afasia e infância - na qual nos debruçamos neste texto prosseguindo nessa inter-relação concebida por estudos clássicos.

\section{INV: Vamos escrever seu sobrenome? \\ EA: Sobrenome? \\ INV: Qual é o seu sobrenome? \\ EA: Seu sobrenome é Abaurre.}

A questão discursiva posta nesse dado ocorre quando EA hesita diante da reversibilidade de posições discursivas. ${ }^{16}$ Mostra que a afasia envolve a subjetividade e a alteridade (BENVENISTE, 1966), tal como propõe Coudry (1986).

${ }^{13}$ Agradecemos a você, Maria Bernadete, que contribuiu muito para a teorização e análise de dados da ND, com sua participação em bancas (mestrado, doutorado, qualificação de área), compondo com as autoras deste texto uma discussão que refinou a teorização e o desenho metodológico, além de demandar mais contradispositivos de nossa parte.

${ }^{14}$ Consequência de um AVCi em região posterior do hemisfério esquerdo.

${ }^{15}$ Um inesquecível fim de semana em Vitória, junto à família nuclear de EA, na parte que se constitui das 5 Marias: Angélica, Bernadete, Sílvia, Luísa e Lúcia.

${ }^{16}$ Isso retorna em dados de EA ao explicar provérbios, compreendendo ou não suas metáforas, e ao construir narrativas de vida. 
Coudry sugere a EA que escreva, com letras móveis, seu sobrenome e ele escreve Abarre. MB leu como ele escreveu e lhe pergunta o que falta. Imediatamente ele disse: $o L$, e MB lhe pergunta: $o L$ ? Não, $o U$, ele disse de pronto (e todas as Marias comemoram...). Nesse lapso de hesitação EA se lembrou da escrita inicial, onde cabe tomar U por L, e vice-versa, como coda silábica (voutol; resouvel). Isso também ocorre nos dados de escrita de afásicos que experimentam a indiferenciação, o que também acontece com iniciantes de escrita, como mostram Abaurre (2001) e Abaurre e Coudry (2008), diante do registro permanente da escrita oficializado pela ortografia.

A fala de EA é relativamente fluente, com alguma imprecisão articulatória (sequela do déficit neurológico motor e sensorial sobre o funcionamento dos fono-articuladores), mas não compromete sua inteligibilidade, exceto se está cansado. Ele compreende bem a fala do outro e a retoma de vez em quando para organizar seu dizer. Lê e escreve com dificuldade porque a lesão posterior prejudica a análise do que vê e a posição de objetos no espaço. Além disso, a relação fonográfica, base do sistema alfabético, foi desautomatizada e a espacialidade da escrita desorganizada. Essa condição faz com que demore mais tempo para localizar o U dentre outras letras, embora saiba qual é a letra, e que hesite diante da ordem das vogais em sílabas CVVV, por exemplo. Para escrever raio, escreve primeiro rioa e depois roia. Diz silabicamente ra-io, como fazem as crianças, olhando para o que havia escrito e reordena as vogais na palavra, tendo a fala orientado essa reordenação.

EA não soletra, não decompondo a palavra em letras. Soletrar por si mesmo ainda não é uma entrada para ele voltar a escrever, como acontece no início da alfabetização, antes da escrita automática, que prescinde desse apoio. Mas EA escreve palavras se seu interlocutor soletrar para ele e lê as letras se estão separadas. Um caminho se abre, então, para retomar a escrita de palavras.

Coudry lhe sugere que pense na palavra e não a escreva de imediato, mas se debruce sobre sua forma, visualizando-a. Ele pensa em uma palavra e a escreve: "hoje" como hoie, em que se vê a semelhança visual interferindo na escrita. Imediatamente corrige. Nesse caminho de volta à escrita EA faz coisas que as crianças fazem: encontro inevitável.

EA, como outros afásicos e crianças, nos fazem ver o que não víamos e fazem avançar o movimento entre teoria, processo de descoberta e dado singular/ achado.

\section{REFERÊNCIAS BIBLIOGRÁFICAS}

ABAURRE, M. B. M. Ritmi dell'oralità e ritmi della scrittura. In: ORSOLINI, M.; PONTECORVO. C. La costruzione del testo scritto nei bambini. Roma: La nuova ltalia, 1991, pp. 77-98.

ABAURRE, M. B., Dados da escrita inicial: indícios de construção da hierarquia de constituintes silábicos? In: HERNANDORENA, C.L.M. Dados da escrita inicial: indícios de construção da hierarquia de constituintes silábicos? Pelotas: EDUCAT/ ALAB, 2001.

ABAURRE, M. B. Ritmo e linguagem. In: ALKMIN, T. COUDRY, M. I. H.; POSSENTI, S.; (Orgs.). Saudades da Língua, Campinas: Mercado de Letras, pp. 85-94, 2003. 
ABAURRE-GNERRE, M. B. Processos fonológicos segmentais como índices de padrões prosódicos diversos nos estilos formal e casual do português do Brasil. In: Caderno de Estudos Lingüísticos, 2: $23-34,1981$.

ABAURRE, M. B. M. \& COUDRY, M. I. H. Em torno de sujeitos e olhares. In: Estudos da Língua(gem), v. $6, \mathrm{n}^{\circ} 2,171-191,2008$.

ABAURRE, M. B., FIAD, R. S., MAYRINK-SABINSON, M. L. Cenas de aquisição da escrita. Campinas: Mercado de Letras, 1997.

AGAMBEN, G. O que é contemporâneo? e outros ensaios. Trad. Bras. Vinicius Nicastro Honesko. Chapecó: Argos, 2009.

ALKMIM, T. M.. Língua portuguesa. Objeto de reflexão e de ensino. Cefiel/IEL/Unicamp, 2009.

AMARAL, A. S., FREITAS, M. C. C., CHACON, L., RODRIGUES, L. L. Omissão de grafemas e características da sílaba na escrita infantil. In: Rev. CEFAC, v. 13, nº 5, 846-855, 2011.

BAKHTIN, M. Estética da criação verbal. Tradução de Paulo Bezerra. 4. ed. São Paulo: Martins Fontes, 2003.

BARBOSA, P. Syllable-timing in brazilian portuguese: uma crítica a Roy Major. In: D.E.L.T.A., vol. 16, n. $^{\circ} 2,369-402,2000$.

BARBOSA, P. Ritmo da escrita e ritmo da fala: congruências e não congruências. In: Domínios de Lingu@gem (http://www.seer.ufu.br/index.php/dominiosde linguagem) v.7, n, 2 , pp. 47-70, 2013.

BENVENISTE, E. (1966) Problemas de Linguística Geral I. Trad. Maria da Gloria Novak e Luiza Neri, São Paulo: Editora USP, 1995.

BISOL, L. O troqueu silábico no sistema fonológico. In: D.E.L.T.A., São Paulo, v. 16, n. 2, 2000.

BORDIN, S. S.; COUDRY, M. I. H. Excluir para depois incluir In: BARROS, R. C. B. e MASINI L. (Orgs.) Sociedade e Medicalização.1 ed. Campinas: Pontes Editores, 2015, v.1, pp.129-146.

CAGLIARI, 1. C. Existem línguas de ritmo silábico? In: Estudos Linguísticos. São Paulo, 42 (1): pp. 19-32, jan-abr, 2013.

CHACON, L. Ritmo da escrita: uma organização do heterogêneo da linguagem. São Paulo: Martins Fontes, 1998.

CORRÊA, M. L. G. O modo heterogêneo de constituição da escrita. São Paulo: Martins Fontes, 2004.

COUDRY, M. I. H. (1986) Diário de Narciso. Discurso e afasia: análise discursiva de interlocuções com afásicos. Tese de doutorado. Unicamp, Campinas, 1986. Publicada em livro, São Paulo: Martins Fontes, 1988.

COUDRY, M. I. H. O que é dado em neurolingüística?. In: CASTRO, M. F. C. (Org.) O Método e o dado no estudo da linguagem. Campinas, SP: Editora da Unicamp, 1996. pp. 179-192.

COUDRY, M. I. H. Afasia como tradução. Estudos da Língua(gem), v. 6, n 2, 7-36, 2008.

COUDRY, M. I. H. Caminhos da Neurolinguística Discursiva: o velho e o novo. In: COUDRY, M. I. H.; FREIRE, F. M. P.; ANDRADE, M. L. F.; SILVA, M. A. (Orgs). Caminhos da Neurolinguística Discursiva: teorização e práticas com a linguagem, 1 ed. Campinas: Mercado de Letras, 2010, pp. 279-399. 
COUDRY, M. I. H; BORDIN, S. S. Afasia e Infância: registro do (in)esquecível. Cadernos de Estudos Linguísticos, v. 54 (1), pp.135-154, 2012.

COUDRY, M. I. H., SCARPA, E. M. De como a avaliação de linguagem contribui para inaugurar ou sistematizar o déficit. In: Cadernos Distúrbios da Comunicação, Série Linguagem, v. 2. São Paulo: PUC, 1985.

CULIOLI, A Pour une linguistique de l'énonciation: formalisation et opérations de repérage, v. 2. Paris: Ophrys, 1999.

DE LEMOS, C. Interacionismo e aquisição da linguagem. In: D. E. L. T. A., v. 2, n. 2, pp. 231-48, 1986.

FARACO, C. A. Linguagem escrita e alfabetização. São Paulo: Contexto, 2012.

FOUCAULT, M. (1969). Arqueologia do Saber. Trad. de Luiz Felipe Baeta Neves. Rio de Janeiro: Forense, 1987.

FREIRE, F. M. P., KOBAYASHI, A., GARCIA, B. L., COUDRY, M. I. H. Entre lápis e teclas: selecionando e combinando letras. Cadernos de Estudos Linguísticos, v. 55, pp. 45-65, 2013.

FREUD, S. (1891). Pour concevoir les aphasies. Une étude critique. Traduction de Fernand Cambon. Paris: EPEL, 2010.

HELLER-ROAZEN, D. (2005) Ecolalias: sobre o esquecimento das linguas. Trad. Fabio A. Durão. Campinas (SP): Editora UNICAMP, 2010.

JACKSON, H. On the nature of the duality of the brain. In: Brain, v. 38, ns. 80-86; 87-95; 96-103, 1874.

JAKOBSON, R. (1941) Langage enfantin et aphasie. Paris: Flammarion, 1980.

LABIGALINI, A. P. V. Reflexões sobre a práxis fonoaudiológica à luz da Neurolinguística Discursiva. Campinas-SP: Instituto de Estudos da Linguagem, Universidade Estadual de Campinas (Dissertação), 2009. 125p.

LURIA, A. R. Neuropsychological Studies in Aphasia. Amsterdam: Swets \& Zeitlinger B.V, 1977.

LURIA, A. R. O desenvolvimento da escrita na criança. In VYGOTSKY, L. S.; LEONTIEV, A. N. e LURIA, A. R. Linguagem, desenvolvimento e aprendizagem. 3a. ed. São Paulo: Ícone, 1988.

MASSINI-CAGLIARI, G.; CAGLIARI, L. C. Diante das letras - a escrita na alfabetização. São Paulo: Ed. Fapesp, 2001.

MIGLIORINI, L.; MASSINI-CAGLIARI, G. Sobre o ritmo do português brasileiro: evidências de um padrão acentual. In: ReVEL, v.8, n15, 2010 (www.revel.inf.br).

POSSENTI, S. Aprender a escrever (re)escrevendo. São Paulo: Cefiel/IEL/Unicamp e MEC, 2005. 